\title{
EDUCACIÓN CÍVICA Y CIVILIDAD: UNA TENSIÓN MÁS ALLÁ DE LOS TÉRMINOS
}

\begin{abstract}
Resumen
La política educativa en Colombia ha insistido en la urgencia de una formación ciudadana, en sus marcos, parámetros y contenidos mínimos. Las prácticas educativas resultantes demandan preguntar si, con la relevancia de una educación ciudadana, se ha generado la atmósfera necesaria para la emergencia de una civilidad que trascienda la prescripción enseñada. La concepción de civilidad ha variado: con el paso de barbarie a civilización, el concepto se transforma en denominación de trato agradable de conformidad con lo esperado, y con la llustración se constituye en elemento de la esfera de lo público. Una acepción contemporánea refuerza el sentido de justicia y de pertenencia. La civilidad no se agota en el abordaje semántico. Si la civilidad no emerge como emancipación política para la construcción de lo público, la educación cívica mantendrá su carácter prescriptivo y la formación ciudadana su carácter instruccional. Este artículo forma parte de la investigación "Educación superior y formación ciudadana, caso Bogotá". Se compone de tres apartados: conceptualizaciones y tránsitos de términos, conceptos y relaciones; realizaciones de educación cívica y ciudadana en Colombia; y un recorrido entre las tensiones: la civilidad como emergencia de la función crítica y como tarea política.
\end{abstract}

Palabras claves: Civilidad, ciudadanía, educación, política.

\section{EDUCAÇÃO CÍVICA E CÍVICA: A TENSÃO PARA ALÉM DAS CONDIÇÕES}

\section{Resumo}

A política educativa em Colômbia insistiu na urgência de uma formação do cidadão, em suas marcas, parâmetros mínimos e índices. As práticas educativas exigem perguntar-se pela relevância da instrução do cidadão e atmosfera necessária para a emergência de uma civilidade a ser gerada que estenda a prescrição. A concepção da civilidade variou: do conceito da passagem do barbarismo à civilização, é transformado na denominação de tratamento agradável de conformidade com as coisas esperadas. A civilidade não se esgota no abordagem semântico. A civilidade não emerge como emancipação política para a construção do público, a instrução cívica mantém seu prescrição do caráter e a formação do cidadão seu caráter do instrucional. O artigo faz parte da investigação "formação superior da instrução e do cidadão, caso Bogotá". Um é composto de três seções: conceptualizaciones e trânsitos dos termos, dos conceitos e das relações; realizações da instrução civic e do cidadão em Colômbia; rota entre as tensões: o civilidad gosta da emergência da função crítica e como a tarefa política.

Palavras chaves: Civilidad, citizenship, instrução, política.

* Docente Universidad de la Salle, Facultad de Ciencias de la Educación. Doctora por la Universidad de Salamanca: Política educativa ante el relevo milenario. Correo electrónico: gcvg18@yahoo.es

** Docente Universidad de la Salle, Facultad de Ciencias de la Educación y Universidad Pedagógica Nacional, Facultad de Educación. Maestría en Lingüística, Instituto Caro y Cuervo. Correo electrónico: lili.canon@hotmail.com

*** Docente Universidad Pedagógica y Tecnológica de Colombia. Doctorando en Ciencias de la Educación, Rudecolombia. Correo electrónico: camolina0411@hotmail.com

Artículo recibido el 16 de abril de 2009 y aprobado el 17 de junio

Pedagogía y Saberes N.² 28. Universidad Pedagógica Nacional. Facultad de Educación, 2008, pp. 81-90 


\title{
CIVIC EDUCATION AND CIVILITY: A TENSION BEYOND THE TERMS.
}

\begin{abstract}
The educational policy in Colombia has insisted on the urgency of a citizen formation, in its frameworks, parameters and minimum contents. The resulting educative practices demand to ask if with the relevance of a citizen education the necessary atmosphere for the emergence of a civility has been generated that transcends the prescription taught. The conception of civility has varied: from the concept of the passage of barbarism to civilization, it is transformed into denomination of pleasant treatment according to the awaited thing. With the lllustration it is become element of the sphere of the public. A contemporary meaning reinforces the sense of property and justice. The civility is not finished at semantic boarding. If the civility does not emerge like political emancipation for the construction of the public, the civic education will keep its prescriptive nature and the citizen formation its instructional nature.

This article is part of the research: "Higher Education and Citizen Formation in Bogota". It is made up of three sections: conceptualizations and transits of terms, concepts and relations; accomplishments of civic and citizen education in Colombia; route between the tensions: the civility like emergence of the critical function and political task.
\end{abstract}

Key words: Civility, citizenship, education, policy.

\section{LOS ÁMBITOS DE LAS TENSIONES}

\section{La tensión de las acepciones}

Las acepciones del término civilidad han variado a través del tiempo; del mismo modo, su valor sociopolítico. Interrogar acerca del sentido de civilidad podría generar respuestas que se moverían en los campos semánticos de ciudad, civilización o ciudadanía -al respecto se puede aducir que establece relaciones con tales términos, pero que no puede tomarse como sus sinónimos-; tal vez otras afirmaciones conducirian a asociar el término con un neologismo propio de los derechos humanos o podría asociarse a un arcaísmo; ni lo uno ni lo otro. Habría que preguntarse, entonces, acerca del porqué de su infrecuente uso o del desparpajo en su apreciación semántica.

El diccionario de la Real Academia vincula civilidad con sociabilidad y urbanidad. El primer término se refiere al trato, a la relación con las personas o a la inclinación hacia ellas; el segundo, se entiende como comedimiento, atención y buen modo. Así, civilidad pareciera relacionarse con actos de cortesía, con manifestaciones de atención, respeto o afecto de una persona hacia otra.

Según María Moliner, civilidad comparte raíz latina con civis -ciudadano, miembro del Estado, compatriota-y con civitas-ciudad, reunión de ciudadanos; cuerpo político, Estado, patria; derecho de ciudadanía-. Por ende, el término se asocia con civismo.

\section{La tensión del concepto}

Además de las posibilidades de la formalización lexicográfica, la acepción política de civilidad involucra aspectos de las tradiciones liberal y republicana en relación con la educación cívica; refuerza el concepto de justicia en cuanto a leyes, derecho y sentido de pertenencia. Así, para Adela Cortina, civilidad significa "reforzar el acuerdo entre los ciudadanos en torno a una noción de justicia, con el fin de fomentar su sentido de pertenencia a una comunidad y su afán de participar en ella" (citada por Barba M. 2006, p. 197). En esta definición se trasciende la cohesión social lograda mediante el derecho y se aproxima a una "libre adhesión y participación de los ciudadanos".

Con base en lo anterior puede establecerse, como punto de partida, una escala gradual en las acepciones de civilidad. En el contexto de la enseñanza mediática de los valores, en especial dirigida a una población infantil, la Fundación Televisa (2008) ha realizado un listado de valores de la A a la Z en el cual agrupa civilidad con orden, urbanidad y cortesía para establecer una escala de tres niveles:

En la superficie se hallan la urbanidad y la cortesía, un conjunto de normas fáciles de aprender y seguir: cuidar la higiene y apariencia personales, hablar con amabilidad a los demás personas y comer con buenos modales. En el siguiente plano se encuentra el orden: la organización de las actividades y proyectos de manera que tomen en consideración los de los demás. En el nivel más profundo está la civilidad: la capacidad de llevar la cortesía, el respeto y el orden a toda la sociedad en su conjunto y crear un clima propicio para la convivencia y la participación.

En ciertos contextos históricos, el concepto de civilidad se ha identificado con civilización como opuesto de barbarie. Ésta se transformará con la educación y así se sacará del estado de ignorancia a una población. En igual sentido, se contrapone a natura; es decir, se reconoce la civilidad como construcción cultural.

Fernando Mirés (2001) señala que en Grecia y Roma clásicas la política era esencialmente participativa; en la actualidad es delegativa/contractual. Se puede inferir que ciudadanía y política eran interdependientes e interrelacionadas y que ahora la relación no es tan directa. El ciudadano, en sentido griego, por ser libre, tenía el derecho y el deber de la ciudadanía: ejercía la política. La profesionalización de la política en la contemporaneidad deviene en ciudadanos que delegan en otros. Los espacios de acción política contemporánea responden a dos ámbitos: el estatal, ejercido por profesionales de la política, y el de 
los ciudadanos, quienes realizan actos de "politicidad" que trascienden lo electoral. Tales actos son posibles en virtud de la presencia de la civilidad como pilar sobre el cual se realiza la ciudadanía.

Durante la llustración, civilidad se relacionaba con comportamientos públicos en una concepción de vínculo social instituido en el contrato: la cualidad de buen ciudadano (cortés y educado) que respeta y acepta los valores y las reglas establecidas por las instituciones y la democracia.

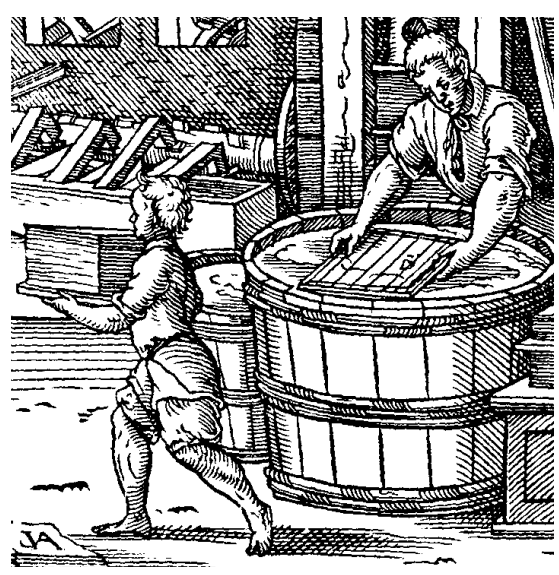

Kant relacionó en 1784 la dimensión social de la civilidad con la dimensión política del civismo (Citado por Villavicencio S. 2007, p. 40): la vigencia de una ley común se deriva de la organización de una instancia política que sancione los comportamientos sociales. De este modo, civilidad, civismo y espacio público de crítica configuran los fundamentos del republicanismo moderno cuando delimita una esfera pública opuesta a las formas de dominio privado.

La civilidad atravesó un momento histórico único, según Adorno, cuando la burguesía se liberó del "Viejo Régimen" y emergió una forma de individualidad expresada en la capacidad de relacionarse con el otro de forma plena y con respeto (Adorno, 2004). Dicha civilidad habría de exhibirse en una "dialéctica del tacto" en la cual la propia conducta se modula respecto del otro, pues se retiene y se autolimita a partir del juicio realizado acerca de los límites que se tienen en el desarrollo de una individualidad autónoma. Para Adorno esta dialéctica de la civilidad se desgastó con el crecimiento del individualismo burgués: se diluyó la capacidad consciente del individuo de renunciar a ciertos actos en nombre del respeto y de la dignidad del otro.

Desde el liberalismo, los derechos individuales derivan de la naturaleza de la persona y no pueden sacrificarse en aras del bien común. En la universalidad del individuo, como sujeto de derecho, prima la justicia sobre otros bienes. Por su parte, para el republicanismo el ciudadano se configura en una práctica de la ciudadanía donde lo público y lo privado convergen. Esta práctica no es natural y exige educación y motivación, según indica Bárcena (1997, p. 144). En esta concepción, la primacía no está en la justicia sino en el bien común.

En tal contexto, el concepto de civilidad se abre hacia las condiciones de convivencia y de este modo emergen entre otros vinculantes la solidaridad, el respeto entre los miembros de una comunidad y la atención a la diversidad. La civilidad se condiciona por la realización del principio de igualdad política de los ciudadanos; principio que

[...] no es el resultado de una condición natural que preceda a la constitución del ámbito público [...] es un atributo artificial que adquieren los individuos cuando acceden a la esfera pública y que es asegurado por las instituciones democráticas (Bárcena, 1997, p. 211).

\section{La tensión de las relaciones}

Civilidad/ciudadanía constituyen un bucle recursivo que establece interacciones, interdependencias y emergencias de lo público, sobre lo público, para lo público y acerca de lo público. Se establece un circuito en el cual la acción política ciudadana produce y es producida por las relaciones de reconocimiento mediante el trámite no violento de conflictos y un "cuidado del otro" actualizado que trasciende las buenas maneras, la cortesía y el orden para ocuparse del otro y de lo otro, desde el reconocimiento y la acción combinadas.

En la actualidad se viven diversos fenómenos que, en conjunto, tienen implicaciones para la comprensión y la realización de las relaciones ciudadanía/ civilidad: movilidad humana generalizada, diversificada y en crecimiento; expansión y restricción del ejercicio de los derechos y los deberes; reconfiguración del papel, del alcance y de los límites del Estado Nación; multiplicidad de núcleos de la política y su tránsito del papel rector al papel mediador; globalización económica y mundialización de la cultura; modificación de los espacios y de los tiempos facilitada por las tecnologías de la información y de la comunicación donde se genera cierta "fabulación" de la vida cotidiana y se facilita la delimitación borrosa de lo público y de lo privado ${ }^{1}$.

De igual modo, la heurística de "ciudadanía" lleva a preguntarse si, tal como ocurre con "civilidad", la variedad de fenómenos que permiten una amplia utilización del término admiten, de igual modo, hacer referencia a conceptos similares. Si se comprende la ciudadanía como el ejercicio de derechos y deberes de los sujetos en relación con un(os) Estados(s) determinado(s) en un territorio particular, que privilegia de modos distintos al individuo y al colectivo, se hace evidente que los fenómenos señalados y la movilidad conceptual indicada anuncian la emergencia de modos de ciudadanía no realizados: movimientos ciudadanos en perspectiva de género, en perspectiva ambiental, en jurisprudencia internacional, en organización de movimientos de tipo indigenista o afrodescendiente. De igual modo, el papel de los Estados, la mediación de la política y el lugar del sujeto-ciudadano se han diversificado y se ha trascendido una de las características propias de la ciudadanía: el vínculo entre un territorio, un estado y un(os) ciudadano(s).

Así, la ciudadanía se vincula, entonces, con el habitar; y los modos de habitar, comprender y apropiar el territorio son diversos, de acuerdo con la experiencia subjetiva y colectiva de los sujetos. Aho-

1 El mercado ha impuesto modos de relación política dentro de los Estados, entre Estados y en el ejercicio de lo ciudadano, pues interviene en la configuración de reglas de consumo, de participación, de identificación y de comportamiento. 
ra bien, movilizar el ejercicio hermenéutico interpretativo de ciudadanía hacia los márgenes coadyuva a una comprensión de ciudadanía en la cual los modos del habitar cobran tanta importancia como el ejercicio de los derechos y los deberes. Es más, éstos últimos se realizan en virtud de las experiencias de la "habitancia".

Los nexos entre ciudadanía y civilidad, aunque con límites a veces difusos, trascienden el ámbito que fundamentan la ética de la construcción y de la práctica ciudadana propia de lo republicano. De igual forma, se alejan de la diferenciación entre bárbaros y civilizados. Tampoco se ubican en una apología al individualismo que niega la otredad, lo cual consolidaría experiencias sociales contemporáneas de supervivencia del más fuerte, "del más vivo", "del más 'avión'”, "del menos tonto".

Etiènne Balibar (2003) sustenta la necesidad de articular civilidad con ciudadanía. El ejercicio de la ciudadanía actualiza relaciones de civilidad y éstas, a su vez, posibilitan ejercicios de ciudadanía.

\section{COLOMBIA, UN TOPOS PARA LAS RELACIONES ENTRE EDUCACIÓN CÍVICA Y CIVILIDAD}

\section{Dos siglos de educación cívica.}

En estos casi 200 años de vida republicana se ha profesado en Colombia una educación cívica de carácter terapéutico, impartida sobre la base de que se requiere un nuevo tipo de ciudadano para construir un "nuevo" orden. Calidad "terapéutica" derivada de considerar que se hace posible un nuevo orden sólo con actores saneados. En consecuencia, la educación cívica se ha realizado para regenerar y posibilitar el surgimiento de un "hombre nuevo", saneado para el funcionamiento de las instituciones ${ }^{2}$.

2 Según esta idea, sólo será posible construir el bien común si todos los miembros de la sociedad actúan pensando en el
La educación cívica cumpliría, entonces, las funciones de regeneración moral y socialización. La primera conduciría a variar las motivaciones de los sujetos para sustituir valores morales; la segunda socializaría a sucesivas generaciones en el nuevo ethos construido y aplicaría correctivos.

Según Hurtado y Álvarez (2006), uno de los rasgos centrales de la educación cívica en Colombia, desde 1810, ha sido poner a la escuela como el epicentro de la formación ciudadana, bajo los supuestos de que los sectores populares requieren ser controlados, civilizados 0 contenidos en sus demandas, y de que la educación se encargaría de rescatarlos de su condición. Esta perspectiva podría vincularse con civilidad opuesta a un supuesto estado de barbarie que se transforma por medio de la educación.

Entre 1810 y 1850 los dirigentes de la nación recién independizada tuvieron conciencia del problema de la educación cívica que debían enfrentar; pusieron énfasis en la "civilización" y en la formación de una conciencia ciudadana mediante la enseñanza de obediencia a unos valores republicanos necesarios para la construcción de una nación. Para ello se requería cambiar las lealtades de los nuevos ciudadanos hacia la clase dirigente y alcanzar la apropiación de los procedimientos de una república democrática -elecciones, división de poderes, partidos políticos, Constitución-. Se debían aprender formas de participación política basadas en un novedoso y desconocido paradigma político.

En tal proceso, los estudiantes debieron aprender las reglas de conducta cívica tal como memorizaban el catecismo: bajo la forma dogmática de preguntas y respuestas cerradas ${ }^{3}$. Los textos de la época permiten apreciar las tensiones entre urbanidad - civilidad, sociabili-

bien común, y sólo será posible construir una sociedad justa si todos los individuos actúan en función de un ideal de justicia". (Cfr. Da Silveira, 2003).

3 La palabra catecismo viene de la voz griega kathejismós, que significa "repetición de viva voz". dad-, educación moral -formación en valores ligados al ideario católico-e instrucción cívica -constitución de comunidad política- (Herrera, Pinilla y Suaza, 2003, p. 98).

Durante el régimen radical se pretendió contrarrestar la educación impartida desde la Colonia por la Iglesia Católica. Los liberales radicales concibieron e impulsaron un sistema escolar para formar ciudadanos y enfrentar una enseñanza cívico-religiosa que inculcaba valores contrarios a los exigidos, precisamente, por la democracia liberal.

A partir de la Regeneración se elaboró una combinación conceptualmente superpuesta: enlace de la tradición cristiana del bien común con principios liberales. La conjunción y la confusión de estas tendencias incorporaron, por ejemplo entre 1886 y 1958, valores de ciudadanía en modelos políticos tanto de origen escolástico como antiliberal. Durante el Régimen Conservador (18861930) se instauró un orden jerárquico centralizado que construyó las relaciones entre el Estado y la Nación sobre la base de los preceptos de la Iglesia Católica (Melo, 1991). Se tejió una arraigada relación entre identidad nacional y religión católica que otorgó a la Iglesia el control ideológico de la educación. Los derroteros de la formación ciudadana se orientaron hacia el moldeamiento de hombres productivos que fuesen servidores del Estado y devotos cristianos.

En la escuela colombiana de cambio de siglo se enfatizó en la enseñanza de una educación cívica que pretendía educar a los ciudadanos en las virtudes cívicas a partir del reconocimiento de los símbolos patrios y del seguimiento de la tradición nacional tamizada por la tradición cristiana. Se pusieron límites al individualismo liberal y al igualitarismo democrático; se enseñaron valores cívicos a partir del reconocimiento de los signos y emblemas del país; las prácticas democráticas se centraron en la realización y en la participación de actos referidos a la conmemoración de la Independencia, el saludo a la bandera y la entonación del Himno Nacional. 
Con posterioridad a 1910 , se pretendió una educación cívica basada en la urbanidad y en el esfuerzo por educar en normas de buena conducta y comportamiento social: cómo aprender a distinguir en la calle a la persona noble, a quién se puede o no mirar a la cara, a quién se le debe ceder el paso en la acera y a reconocer las jerarquías (Londoño, 1997). Tal como se señaló en la tensión de las acepciones, la civilidad se vinculó con urbanidad comprendida como comedimiento, atención y buen modo, cortesía, atención y respeto de una persona hacia otra.

La República Liberal (1930-1946) impuso a la escuela el desafío de educar en democracia desde el ejercicio de la participación al interior de la institución. Se dio paso a la creación e implementación de dispositivos y estrategias como el periódico escolar y la conformación de un gobierno escolar con elecciones de representantes.

Al respecto, Jorge Orlando Melo (2002) recuerda el papel que jugó "La alegría de leer":

En su edición de 1933 ó 1934, de acuerdo con las orientaciones del gobierno, dice que, como escuela de democracia, en toda escuela debe establecerse el gobierno escolar y debe haber una elección en la cual se elija a su presidente. Ya entonces se decía que no bastaba enseñar unos contenidos, sino que era necesario que los estudiantes aprendieran mediante la participación real, la discusión de problemas, el ejercicio de elegir unos representantes, la publicación de un periódico, etc. los elementos que los prepararían para una participación democrática en la sociedad real.

El trámite de los conflictos de mediados de siglo no dio cuenta de la educación cívica promovida por esos 20 ó 30 años de enseñanza basada en los planteamientos de "La alegría de leer". Por el contrario, la década de los años 50 marcó la re-toma del poder por parte de gobiernos conservadores que reimplantaron procesos de socialización política a través de sermones en los púlpitos, de rencillas callejeras y familiares a nombre del Sagrado Corazón o de los partidos tradicionales y casi con la primacía del aniquilamiento del adversario. Durante este período, indica Melo (2002), Colombia vivió, además, la única dictadura militar del siglo $\mathrm{XX}$ marcada por el intento de sustituir la educación cívica por la Cátedra Bolivariana y las cátedras de hispanidad.

A pesar del esfuerzo del liberalismo por privilegiar la educación cívica, de la intención conservadora por re-cristianizar el país y de la gravedad del conflicto partidista, durante la primera mitad del siglo XX se produjo una separación entre los contenidos formales y los ideales promulgados en la educación cívica. Educación cívica que tuvo, además, connivencia con experiencias cotidianas signadas por el abuso de la fuerza, la presencia de la ilegalidad, el ejercicio del autoritarismo y de la intolerancia; por ende, Colombia contó con una educación cívica que desconoció los latentes rasgos autoritarios y jerárquicos incorporados en la dimensión cultural de la nación.

El Frente Nacional no sólo estableció una práctica democrática de unificación partidista; el interés por aplacar la discusión partidista repercutió en una ausencia de debates respecto de las finalidades educativas. Al mismo tiempo se introdujeron discursos tecnocráticos que entendieron la educación como capital humano y la educación ciudadana al servicio de la formación productiva (Cfr. Herrera, 2008).

En las décadas de los años 70 y 80, la educación cívica mantuvo cierta continuidad. Los estudios sociales -historia, geografía, educación cívica y social, sociología, psicología, filosofía y ética- se desagregaron en los años 70; persistieron sólo historia, geografía y cívica (Cortés, 2007). En los años 80 se constituyó el área de ciencias sociales y se creó el programa de educación para la democracia, la paz y la vida social.

Durante ese período la educación cívica y la educación para la democracia se ampliaron hacia diversidad de programas de formación ciudadana y escuelas de liderazgo democrático, coordinadas y orientadas por organizaciones no guber- namentales, por gobiernos locales o por alianzas entre ambos. Propuestas direccionadas desde la educación no formal que contaban con currículos particulares y desarrollaban programas específicos. Sin embargo, las circunstancias sociales y políticas de la época impidieron ver estas escuelas de ciudadanía como tales y fueron a parar al lugar estigmatizado de lo ingobernable, de lo extraño y lo peligroso (Hurtado y Álvarez, 2006).

Durante las décadas de los años 80 y 90 , la reconfiguración del papel de los Estados Nacionales se enmarcó en los procesos de globalización económica y se dio el giro hacia sociedades posindustriales. Los organismos internacionales marcaron la pauta en materia de políticas públicas relacionadas con ciudadanía a través del desarrollo de competencias ciudadanas medidas con pruebas masivas centradas en estándares internacionales y nacionales. En Colombia, este proceso se combinó con la urgencia de enfrentar la crisis política y moral por la que atravesaba el país y la cual demandaba la urgencia de fortalecer la legitimidad institucional.

\section{LA CONSTITUCIÓN DE 1991, LA DISTANCIA ENTRE EL CIUDADANO Y EL EJERCICIO DE LA CIUDADANÍA}

Valentina Cantón y Mario Aguirre formularon en 1999 desde México un planteamiento que resumiría los ideales asumidos por una formación cívica renovada en Colombia a partir de la Constitución de 1991:

[...] se aspira a la formación de sujetos éticos capaces de expresarse como ciudadanos y ciudadanas abiertos, tolerantes, justos, libres, respetuosos, solidarios, responsables, conscientes de su deuda social, y capaces de reconocerse-desde su identidad, individualidad y dignidad personales- como parte de la humanidad (pasando por el reconocimiento de su familia, entorno inmediato, nación, ambiente ecológico y relación con la Patria-Tierra). Sujetos, en suma, capaces de construir proyectos para lograr una convivencia armónica y mejor vida para y con los y las demás. 
En esa época Colombia participó en la evaluación internacional de conocimientos y actitudes en educación cívica -aplicada a cerca de 90.000 estudiantes de grado octavo, representantes de 28 países- ${ }^{4}$. Los resultados fueron entre ambivalentes y desalentadores: Colombia ocupó el penúltimo lugar en la prueba de conocimientos; sin embargo, en la prueba de actitudes se ubicó como uno de los primeros países en expresar opiniones favorables a la democracia y a la participación cívica (Restrepo, 2001).

La Constitución de 1991 representó una utopía de la participación democrática: se escribieron los ideales que permitirían el tránsito de una democracia representativa a una democracia de participación directa (Melo, 2002). Se introdujeron mecanismos, instituciones, reconocimiento de derechos y recursos legales que entregarían herramientas para instaurar una democracia que trascendiera la formalización del papel, de la ley o de los textos escolares y permitiera la emergencia de un verdadero ethos democrático. La Constitución puso en evidencia la condición de ciudadanos con derechos, la cual había estado diluida en el discurso tradicional: el reconocimiento de derechos expresados en la ley no implicaba su efectiva reivindicación.

Desde la convocatoria para la Asamblea Constituyente, pasando por las discusiones y planteamientos internos, hasta la promulgación de la primera de versión de la Constitución en 1991, el país fue testigo de un acto político que devino en oportunidad histórica no sólo por el nacimiento de

4 Segundo Estudio Internacional de Educación Cívica organizado por la Asociación Internacional para la Evaluación de la Educación -IEA-, institución que, desde la década de los años sesenta, realiza mediciones internacionales en distintas áreas para analizar comparativamente los sistemas de educación con el fin de proveer apoyo a largo plazo para las evaluaciones de políticas. La IEA es el resultado de la asociación del Banco Mundial con organizaciones como la UNESCO, la UNICEF y otras más en los ámbitos nacionales, aunque en diversas instancias se describe y figura como una entidad multilateral independiente

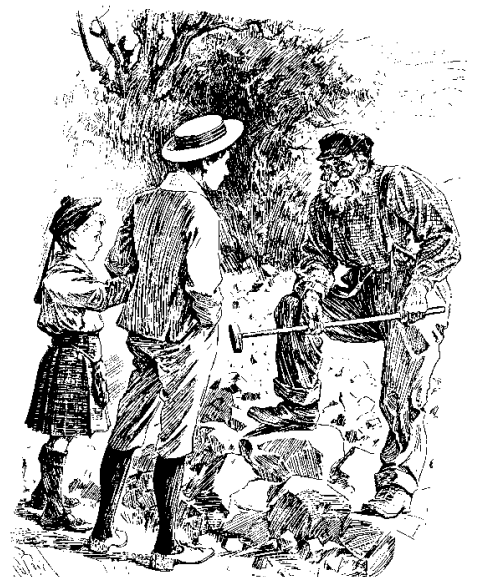

lugar de los problemas, los métodos y los objetos de conocimiento.

La multiplicidad de denominaciones solo es congruente con lo paradójico de los resultados de las pruebas ya señaladas. Se corrobora así que en Colombia coexiste una prolongada tradición de educación escolar de la cívica -retórica y memorística, por cierto- con ejercicios cotidianos caracterizados por actitudes y valores antidemocráticos (Melo, 2002). En Colombia se hace recurrente el uso de un repertorio verbal respecto de la convivencia -respeto, derechos y reconocimiento de las minorías- que se contradice con la ejecución de actos de vida que niegan la ciudadanía misma.

un nuevo texto constitucional, sino porque esta Carta Magna ofrecía mecanismos para adentrarse en la civilidad ${ }^{5}$.

Después de 1991, en continuidad con una tradición de la educación colombiana, se modificaron nombres de asignaturas, se dimensionaron cursos y, al final, se amplió la gama de denominaciones de ese tipo de educación: ciudadana, política, en derechos humanos, para la democracia, para la convivencia, para la participación y para la paz ${ }^{6}$. Modificaciones que pretendieron definir y ampliar los contenidos de una educación cívica como preparación para el ejercicio de la ciudadanía. Sin embargo, se convirtieron en ejemplo de la manera como las fluctuaciones de la política educativa terminan centradas en nombres, en contenidos, en promulgación de normativas y en técnicas, pero se soslaya el valor y el

5 Con "primera versión" se hace referencia a dos aspectos: al texto constitucional no se le permitió desarrollarse en su totalidad pues y, de ahí el segundo asunto, la Carta ha sufrido tantas modificaciones, en especial durante los últimos ocho años, que podría calificarse la actual Constitución como un documento diametralmente opuesto al redactado en 1991.

6 Hurtado y Álvarez (2006) señalan que la formación ciudadana como estrategia educativa cuenta con una larga tradición histórica en Colombia; de igual manera, que tal formación se ha planteado bajo distintas modalidades: civilización, educación cívica, urbanidad, educación democrática, entre otras.
A pesar de contar con una Carta Magna liberal, democrática, participativa y centrada en el reconocimiento del otro, se mantiene en el país una cívica prescriptiva: se adelanta una educación ciudadana instruccional. A la vez, el país se aleja de la configuración de una civilidad que conjugue palabras, acuerdos y acciones para la apertura, la permanencia y la recreación de lo público como ámbito para el reconocimiento y la regulación de los conflictos, un lugar donde la ciudadanía sea posible.

Las propuestas de educación ciudadana inspiradas en la Constitución de 1991 pretendieron renovar el lugar del ciudadano y histórico de democracia y ciudadanía. No significa esto que se hayan cumplido los ideales de ciudadanía planteados por las experiencias educativas. Diversos análisis han hecho evidente que

...los desacuerdos en cuanto a las concepciones y prácticas que [...] deberían regular la educación ciudadana: democracia como armonía versus democracia como conflicto [...] énfasis en la institucionalidad política versus derechos sociales económicos y culturales [...] lo local versus lo universal [...] minoría versus mayoría de edad [...]; dimensión cognitiva-académica versus dimensión vivencial cotidiana [...] lo religioso versus lo secular (Pinilla y Torres, 2006, p. 71).

Los decretos reglamentarios de la Ley 115 de 1994 intentaron superar la enseñanza de la cívica como urbanidad y aprendizaje constituirse en modos de sustituir el déficit 
memorístico de la institucionalidad política; propusieron la escuela como escenario de "educación para la democracia" a través de un currículo relacionado con convivencia, participación en problemas comunitarios, resolución de conflictos, cultura de la legalidad y de la paz y ejercicio de la autonomía, entre otros. De modo simultáneo, se propició el gobierno escolar con la implementación de candidaturas, la discusión programática y las elecciones de representantes y de personeros escolares. Escenario de democracia escolar que puso en marcha la reforma educativa liberal de la década de los años treinta.

Sin embargo, a pesar de la intención participativa de ese proceso, aún se está lejos de una praxis en la cual se puedan crear contextos institucionales necesarios para que las motivaciones que llevan a actuar a los seres humanos -aún si fueran negativas-conduzcan a resultados favorables. Los balances realizados muestran cómo, en gran medida, la experiencia del gobierno escolar ha reproducido el funcionamiento del Estado y el sistema político del país. Junto con ello, el ámbito académico ha persistido en reforzar instrucciones convencionales para inducir las normas, las actitudes y los comportamientos considerados como deseables por la sociedad: los lineamientos curriculares en los componentes de ética, democracia y ciencias sociales están cargados de guías de buen comportamiento ${ }^{7}$.

Tal acto pedagógico solo se acerca al llamado "paradigma de las reglas" en educación cívica: no se cumplen los supuestos que formalmente han creado las condiciones para que, mediante tal educación, se aspire a la construcción de instituciones que hagan posible una convivencia satisfactoria entre los seres humanos ${ }^{8}$.

7 Al respecto, se pueden ver, entre otros, Juan Francisco Aguilar y José Betancourt (2002). Dramas y tramas en el escenario escolar: la transformación innovadora de los conflictos. Bogotá: Innove; y Martha Cecilia Herrera y Carlos Díaz (2002). Educación y cultura política. Una mirada multidisciplinaria. Bogotá: Plaza \& Janés y Universidad Pedagógica Nacional.

8 En educación preparatoria para el
Los dispositivos de educación cívica agenciados durante la década de los años 90 afianzaron prácticas políticas hegemónicas expresadas en la delegación, la escasa argumentación y el mínimo debate para el planteamiento de problemas y de alternativas de solución. Se sigue sin dar respuesta al debate en torno al tipo de ciudadanos que se pretende formar, y desde qué concepciones y perspectivas se orienta tal formación, pues "...la posibilidad de formar ciudadanos exige una reflexión crítica sobre la sociedad, el régimen político y las condiciones reales de existencia de la escuela" (Pinilla y Torres, 2006, p 96).

Al acercarse el fin de la primera década del siglo XXI, la educación para la democracia, la educación cívica, la educación ciudadana y sus diversas denominaciones configuran en Colombia un amplio discurso pedagógico que se esfuerza por extenderse a la cotidianidad, a la vida diaria. Podría decirse que el país cuenta con cierta tradición en la elaboración epistemológica de la ciudadanía, mas no en su construcción epistémica ${ }^{9}$.

Plantear interrogantes, comprenderlos e interpretarlos desde las propias experiencias ciudadanas, sus concepciones, sus realizaciones, sus implica-

ejercicio de la ciudadanía, Da Silveira señala que "mediante el paradigma de las reglas [se establecen] sistemas de reglas que aseguren que el resultado de las acciones individuales (cualesquiera sean los intereses que las muevan) sea satisfactorio en términos colectivos". Da Silveira, Op. cit.

9 La matriz epistémica es un sistema de condiciones del pensar, prelógico o preconceptual, generalmente inconsciente, que constituye "la misma vida" y "el modo de ser", y que da origen a una Weltanschauung o cosmovisión, a una mentalidad e ideología específicas, a un Zeitgeist o espíritu del tiempo, a un paradigma científico, a cierto grupo de teorías y, en último término, también a un método y a unas técnicas o estrategias adecuadas para investigar la naturaleza de una realidad natural o social. En una palabra, que la verdad del discurso no está en el método sino en la episteme que lo define (Martínez, 2001, p 54). ciones y sus derivaciones políticas en elaboración de los propios contextos sigue como tarea pendiente. Elaborar pensamiento epistémico permitiría la emergencia de la civilidad como emancipación, como una política donde se conjugan amabilidad y acuerdo, acciones y palabras.

\section{LA EMERGENCIA DE LA CIVILIDAD EN EL PALIMPSESTO DEL TOPOS COLOMBIANO}

\section{De la ciudadanía por designación al ejercicio de la ciudadanía.}

El agregado sucesivo de desigualdad, violencia, corrupción e impunidad se mantiene y se refuerza constantemente por las especificidades de la condición colombiana. El Estado persiste en negar la existencia de un conflicto armado, en esquivar su tarea de construcción de un proyecto colectivo de nación, en desconocer que su economía tiene fuertes raíces en el narcotráfico, en ver el desplazamiento forzado como un fenómeno de migración social, en no asumir que el deterioro de la convivencia afecta negativamente la construcción efectiva del Estado Social de Derecho. Su realización de democracia no supera la declaración formal -"Colombia, la democracia más antigua de América Latina"- ni la comprensión y construcción del sentido de lo público y del tejido de la civilidad (Talleres del milenio, 2002).

A pesar de ello, el Ministerio de Educación insiste en que los acontecimientos ocurridos en la escuela se pueden proyectar en la dinámica social: la escuela como base de una ciudadanía que se consolidará fuera del aula (MEN, 1998). Pero, en colectivos con mínima civilidad, se hace insuficiente un estilo educativo cimentado en la premisa de que "basta desarrollar contenidos relacionados con ciudadanía para que ella se realice"; aún más dramático se presenta el panorama cuando se prescriben comportamientos, deberes, derechos, formas, mecanismos ciudadanos que desconocen las relaciones entre datos, hechos y fenómenos, y cuando, además, se proscribe aquello que queda 
por fuera de la comprensión hegemónica de lo ciudadano.

En ese contexto poco halagüeño, el Ministerio de Educación promovió la implantación de estándares básicos de calidad

[...] con el fin de que las instituciones educativas cuenten con un referente común que asegure a los colombianos el dominio de conceptos y competencias básicas para alcanzar desempeños satisfactorios en su actividad personal y laboral, vivir en sociedad y participar en ella, en igualdad de condiciones, promoviendo además, el desarrollo de competencias ciudadanas (MEN, 2003).

Al integrar al discurso de la educación ciudadana el concepto competencias, se suma un término más a la cadena de denominaciones de la educación cívica en Colombia.

Con la Constitución de 1991 se hizo visible el hecho de que, en Colombia, los ciudadanos poseen derechos. No obstante, este reconocimiento no encontró correlato en el reconocimiento de los derechos de los otros. En los conflictos colombianos la decisión final adoptada a través de procedimientos democráticos es casi siempre violentada o desafiada por quien dice que la democracia no sirve, o que es una democracia imperfecta y que, por tanto, "mi" derecho a no acoger esa decisión democrática predomina sobre el interés colectivo (Melo, 2002).

Si el ethos democrático de Colombia se fundamenta en un principio de no reciprocidad entre derechos propios y ajenos, se requiere, entonces, soluciones que no impliquen exclusivamente a la escuela. Las reformas aplicadas a la "cátedra de educación ciudadana" han establecido nuevos parámetros en el discurso de ciudadanía, pero además se hace necesario que el sistema escolar incorpore formas de conducta y de participación democrática más allá de los procesos electorales y de las competencias ciudadanas. El proceso democrático también implica una participación cognitiva que conlleve un aprendizaje crítico de las formas del saber.

Un elemento de base en el logro del anterior objetivo se halla en el desarrollo de la capacidad de análisis, de diálogo y de debate dentro del aula. Más todavía cuando en Colombia es regular desconocer, y aún despreciar, los fundamentos de las posiciones contrarias. Es indispensable, además, trabajar en la comprensión, la interpretación y la argumentación; sin desconocer el dominio de las nociones abstractas de convivencia, democracia, género, diversidad o derechos humanos. Al sistema educativo le compete atender de manera más crítica el conocimiento relacionado con el pasado y el presente de Colombia. Más allá de repetir principios o impartir una educación cívica de carácter terapéutico donde se pretenda borrar artificialmente las huellas de una "mala" experiencia anterior, se requiere una subjetivación política y un bagaje conceptual que den sustento a un diálogo democrático en el cual se discuta y se debata desde el reconocimiento de Colombia en su condición socio-geografíca-cultural-política. De este modo se estaría abriendo paso al reconocimiento del otro a partir de la aceptación y del respeto de modos, estilos y principios de convivencia, fundamento del ethos democrático.

Tal vez así se abandonaría el uso de la fuerza como mecanismo expedito y como única opción viable para establecer contacto con las autoridades o con las instituciones cuando se es afectado por las decisiones o las acciones de los otros. Y en ese esfuerzo por pasar de una ciudadanía de designación al ejercicio mismo de la ciudadanía sin mediaciones que perpetúen la corrupción, se estará abriendo camino para disminuir las limitaciones de la democracia que habita en los colombianos.

El ideal de la escuela como institución social es, precisamente, un ideal. La escuela de la cotidianidad se realiza en tensión permanente entre el discurso cívico abstracto y la contradicción con la experiencia diaria individual y colectiva tanto en la escuela como en el barrio, la colectividad y la familia; es un espacio donde contrasta el esfuerzo por hacer del currículo y de la enseñanza dispositivos para promover modos y estilos de convivencia no violentos que se encuentra enfrentado a prácticas gubernamentales y privadas que enseñan la violencia como algo rentable porque paga y porque, en más de una ocasión, resulta ingenuo someterse a las reglas del juego democrático.
Tal vez la ausencia de la pregunta por los rasgos, modos e hilos de la democracia colombiana -no de la teorizada en sus diversas corrientes, sino de aquella proveniente de la fuerza de la propia precariedad (Zemelman, 2007)- permite converger una vez más, y de nuevo, en ese eterno callejón sin salida: los discursos conceptualizan y sustentan abstracciones que entran en contradicción rampante con la experiencia.

Conectar la política y la pedagogía implica una re-politización de la formación ciudadana que pasaría por dos asuntos esenciales: reforzar la idea de formar ciudadanos y formarlos en un determinado enfoque de cultura política (democrática, intercultural, emancipatoria) que reconstruya sentidos; y en segundo lugar, poner en marcha un concepto de "programa político-pedagógico" que favorezca tanto la formación de la subjetividad como la formación política (Hurtado y Álvarez, 2006).

\section{Para navegar entre las tensiones: la civilidad como la emancipación política.}

Para superar las desigualdades en la vida económica y social, Cohen afirma la necesidad de una "revolución en el sentimiento o en la motivación, en oposición a una [mera] revolución en la estructura económica", pues

[...] la justicia no puede ser sólo una cuestión de la estructura legal del Estado dentro del que la gente actúa, sino que es también una cuestión relacionada con los actos que la gente elige dentro de esa estructura, con las opciones personales que llevan en su vida diaria (Cohen, 2001).

De otra parte, Van Parijs, señala que para tener una sociedad justa no sería indispensable que los ciudadanos aceptaran postergar su propio beneficio en virtud de los más necesitados, lo cual es una decisión moral personal (Da Silveira, 2003).

Reconocer los planteamientos de Cohen y de Van Parijs implica aceptar que, en el momento de construir una sociedad justa, son tan importantes las motivaciones colectivas como las individuales. Se marcaría una diferencia frente al paradigma 
terapéutico de la educación cívica en el cual prevalecen las motivaciones particulares, las experiencias de la cotidianidad y los valores que caracterizan al "hombre nuevo" sobre el papel de las normas, que se tornarían en secundarias.

Los postulados expuestos permitirían acudir al tercer paradigma de la educación cívica, el de las virtudes cívicas ${ }^{10}$. En este paradigma la educación ciudadana provee la información cívica, el entrenamiento en habilidades y los conocimientos de las justificaciones normativas que sostienen el diseño institucional $y$, como correlato, se requiere la disposición de jugadores dispuestos a respetar el espíritu de las normas, más que su seguimiento al pie de la letra.

Sin embargo, de esta postura surgen interrogantes: ¿qué valores debe transmitir la educación cívica?, ¿quién los determina?, ¿desde qué parámetros de valoración se analizan la desigualdad, la inequidad, la exclusión? Si el asunto es disponer de lo mínimo, ¿quién determina la base? y ¿cómo se acuerdan los márgenes de movimiento sobre esa base? En colectivos como el colombiano, donde las desigualdades son abismales, la lógica de los mínimos y de los máximos es a todas luces insuficiente.

Emerge entonces el reconocimiento y la puesta en marcha de acciones encaminadas a comprender e interpretar la diada civilidad/ciudadanía y comprender con Balibar la civilidad como emancipación política. Se requiere pensar la política democrática de modo crítico y, para ello, pueden formularse tres conceptos básicos: la conquista de los derechos fundamentales, la transformación de las estructuras de dominación y de las relaciones de poder y la civilidad, entendida como la "producción de las condiciones mismas de posibilidad de la acción política" (Balibar, 2003).

Esta visión implica una relación vinculante de tal diada que se hace aún más urgente en colectivos donde la ausencia de reconocimiento, la marginación y el escaso

10 La propuesta de los tres paradigmas educación cívica se desarrolla en Da Silveira (2003). acceso a condiciones de vida configuran la "infra" humanidad, por cuanto de ese modo se inhiben la acción y el proceso de subjetivación política (Villavicencio, 2007).

Balibar comprende la emancipación como autonomía de lo político. Una autonomía que opera como principio, declarado o no, según el cual una comunidad política existe y puede gobernarse sólo si está libre de una autoridad natural o trascendente. En tal sentido, no es una separación de la esfera del poder y de las instituciones: la distancia está en considerar la política como "el desarrollo de la autodeterminación del pueblo, que se constituye por y en el establecimiento de sus derechos" (Balibar, 2005). Esta dimensión política de la civilidad emerge en relación con la emancipación ligada al sentido y al destino de la comunidad democrática. No es una emancipación vinculada con la pretendida comprensión ilustrada de tránsito hacia la "mayoría de edad" ni con la libertad subjetiva dada por la finalización de la dominación de clases.

Con el concepto de civilidad, Balibar hace referencia a la "heteronomía de la heteronomía" y aborda la política como acción hacia la violencia en sus figuras contemporáneas: por un lado, la violencia sistémica que configura sistema a partir de diversas acciones destructivas -se convierte en forma de tratamiento a las "poblaciones excedentes" del sistema globalizado y globalizante-; por otra parte, se encuentran las formas de violencia "privadas", las cuales rozan la delincuencia o expresan odio social naturalizado y, por ello mismo, no pensado ni criticado.

Estas formas de la violencia, que representan un límite y un bloqueo a las posibilidades de la emancipación, requieren, asimismo, una política de reconocimiento que se implique en las realidades de aquellos seres "sin derechos" y en el límite de su poder. Es, entonces, en el seno de las paradojas de la política democrática que cobra un nuevo sentido el uso de la civilidad, pues es en esta conjunción donde se da la posibilidad o im-posibilidad de la política.

Frente al recrudecimiento de situaciones de violencia generadas (o incrementadas) por la globalización -que cruzan transver- salmente a los Estados (corrupción, tráfico de armas y vidas humanas, migraciones forzadas y formas de no-intervención humanitaria en catástrofes naturales) y provocan situaciones de exclusión en los Estados-nación (deslocalización de la producción, desocupación, pérdida de derechos civiles y sociales o falta de garantías para su ejercicio)- se reitera la insuficiencia de la ciudadanía sin la emergencia de formas de civilidad en la vida colectiva y, viceversa, no es posible expandir la civilidad por fuera del referente institucional de la ciudadanía (Villavicencio, 2007). Así, es necesaria una invención colectiva de la civilidad para configurar una ciudadanía democrática y extenderla a nuevos espacios de socialización; se trata de "vías concretas de civilización de las costumbres y reconocimiento institucional de la igualdad de los derechos" (Balibar, 2003). El núcleo del concepto de civilidad se encuentra en la idea de apertura, creación y re-creación de un espacio público en el cual los diversos agentes se reconozcan y regulen sus conflictos.

Cohn (2003) relaciona civilidad y política como construcción permanente y continua del espacio público digno de ser vivido; en consecuencia, la política se constituye en la construcción conjunta del mundo, la construcción de un orden público condicionado por el conflicto en el cual la civilidad opera como opción frente al individualismo dominante. Así, la civilidad no sólo tiene una función crítica -como denuncia de la pérdida del reconocimiento del otro en la vida colectiva y de la indiferencia como forma de barbarie- sino que se presenta como tarea política en el ejercicio de la ciudadanía.

Colombia ha construido un ámbito de lo público no digno de ser vivido por todos y para todos. Sobre este topos se han superpuesto modos de lo cívico y formalizaciones de lo ciudadano. Ahí, a manera de palimpsesto, la civilidad se abre como potencia creadora: la crítica -reflexión, interpretación, acción-y la política -trámite de la diferencia y del conflicto- desafían a la educación, a las agencias y a los agentes socializadores y educativos para reconocer-se, pensar-se y elaborar-se en un ejercicio de develamiento histórico e historización de sus problemas, de sus interrogantes y de sus soluciones. 


\section{BIBLIOGRAFÍA}

Adorno, T. (2004). Mínima moralia: reflexiones para una vida dañada. Madrid: Akal.

Balibar, E. (2003). Nosotros, ¿ciudadanos de Europa?: las fronteras, el estado, el pueblo. Madrid: Tecnos.

Balibar, E. (2005). Violencias, identidades y civilidad: para una cultura política global. Barcelona: Gedisa.

Barba Martín, L. (2006). Vida buena, vida justa: hacia una ética para la civilidad. Inés Castro (coord.) Educación y ciudadanía, miradas múltiples. México: UNAM.

Bárcena, F. (1997). El oficio de la ciudadanía: introducción a la educación política. Barcelona: Paidós.

Cantón Arjona, Valentina y M. Aguirre BELTRÁn (1999). Formación cívica y ética para la educación secundaria: una propuesta republicana, en Correo del Maestro, Revista para profesores de educación básica, 40 .

COHen, G. A. (2001). Si eres igualitarista, ¿cómo es que eres tan rico? Barcelona: Paidós.

CORTÉs, A. (2007). Entre la instrucción cívica y la educación ciudadana: una aproximación, desde algunos manuales escolares, currículos y disposiciones legales, a la educación colombiana de la segunda mitad del siglo XX. Memorias VIII Congreso Iberoamericano de Historia de la Educación Latinoamericana. Buenos Aires, 30, 31 de octubre 1 y 2 de noviembre de 2007.

Da Silveira, P. (2003). Educación cívica: tres paradigmas alternativos. RubioCarracedo, J.; J. M. Rosales y M. Toscano (edits.) Educar para la ciudadanía: perspectivas ético-políticas. Suplemento 8 de Contrastes, Revista internacional de filosofía, Málaga.

Fraser, N. (2005). Redefiniendo el concepto de justicia en un mundo globaliza- do. M. Escamilla y M. Saavedra (edits.). Derecho y justicia en una sociedad global. Anales de la Cátedra Francisco Suárez, 39, Granada: Universidad de Granada. Sesiones plenarias. Ponencias del 22 Congreso Mundial de Filosofía del Derecho y Filosofía Social.

Fundación Televisa. Civilidad: material para pensar. Calendario de valores 2008-2009. Fundación Televisa (México) [en línea] Disponible en: http://www. fundaciontelevisa.org/valores/pages/ civilidad.html, recuperado el 27 de febrero de 2009

Herrera, M.; A. Pinilla y L. M. Suaza (2003). La identidad nacional en los textos escolares de ciencias sociales: Colombia 1900-1950. Bogotá: Universidad Pedagógica Nacional.

Herrera, M. C. (2008). Esbozos históricos sobre cultura política y formación ciudadana en Colombia: actores, sujetos y escenarios, en Seminario formación y ciudadanía política en Colombia: un reto que no da espera, $17 \mathrm{p}$.

Hurtado Galeano, D. y D. Álvarez Zapata (2006). La formación de ciudadanias en contextos conflictivos, en Estudios Políticos, Instituto de Estudios Políticos, Universidad de Antioquia, 29

Londoño Vega, P. (1997). Cartillas y manuales de urbanidad y del buen tono, catecismos cívicos y prácticos para un amable vivir, en Credencial Historia, 85

MELo, J. O. (1991). Algunas consideraciones globales sobre "modernidad" $y$ "modernización". Fernando Viviescas, (comp.). Colombia el despertar de la modernidad. Bogotá: Carvajal, Foro Nacional por Colombia.

Melo, J. O. (2002). Educación para la ciudadanía: ¿nueva encarnación de un viejo ideal? [En línea]. Disponible en: http://www.jorgeorlandomelo.com/ educacionpara.htm\# ftn3, recuperado el 20 de marzo de 2009.
MIRÉS, F. (2001). Civilidad: teoría política de la post-modernidad. Madrid: Trotta.

Pinilla, A. y J. C. Torres (2006). De la educación para la democracia a la formación ciudadana: una década de incertidumbres. Bogotá: Universidad Pedagógica Nacional, IDEP.

Ministerio de Educación Nacional (1998). Lineamientos curriculares para formación en la constitución política y la democracia: orientaciones para la formulación de los currículos en constitución política y democracia. Republica de Colombia

Ministerio de Educación Nacional (2003). Estándares básicos de competencias ciudadanas. Documento de Trabajo.

Restrepo, G. et Al. (2001). La educación cívica en Colombia: una comparación internacional. Informe presentado al Servicio Nacional de Pruebas, Subdirección de Aseguramiento de la Calidad del ICFES, y al Ministerio de Educación con un análisis de los resultados de la Encuesta Internacional sobre Educación Cívica.

Talleres del Milenio (2002). Repensar a Colombia: hacia un nuevo contrato social. Bogotá, Agencia Colombia de cooperación Internacional - PNUD.

Valencia, G. C. (2007). Alternativas políticas en la formación de sujetos, en Humanidades, Pereira: Universidad Tecnológica de Pereira.

Villavicencio, S. (jul.-dic., 2007). Ciudadanía y civilidad: acerca del derecho a tener derechos, en Colombia Internacional, 66

Zemelman, H. (2007). El ángel de la historia. Cali: Anthropos-UNAM-Universidad de San Buenaventura. 